\title{
A comparison of physiological responses among four cultivars of soybean (Glycine max (L.) Merr.) to single and combined exposure of ozone and peroxides
}

\author{
Cattleya ChutTEAnG*, Prathomrak NA-NGERN*, Masatoshi AOKI*, Shiro HATAKeYAMA*, \\ Nongpat CHAICHANA*, Ruangchai JUWATTANASAMRAN**, \\ and Tiwa PAKOKTOM*** \\ $\left(\begin{array}{c}* \text { Tokyo University of Agriculture and Technology, Fuchu, Tokyo, 183-8509, Japan } \\ * * \text { Maejo University, San Sai, Chaing Mai, 50290, Thailand } \\ * * * \text { Kasetsart University, Kamphaeng Saen, Nakhon Pathom, 73140, Thailand }\end{array}\right)$
}

\begin{abstract}
Crop response to future air pollution stress is important information for crop production in the future. Ozone $\left(\mathrm{O}_{3}\right)$ and peroxides are recognized as significantly damaging air pollutants to plants. Therefore, the present research aimed to investigate the single and combined effects of $\mathrm{O}_{3}$ and peroxides on leaf injury and physiological responses, and to compare the soybean cultivar sensitivities under exposure to single $\mathrm{O}_{3}$ and combined $\mathrm{O}_{3}$ and peroxides. Two Japanese soybean cultivars, Tachinagaha (TC), and Chamame (CM) and two Thai soybeans, A75 and Sorjor 5 (SJ5) were selected as plant materials. Four treatment plots were set up, including a control plot (C plot: free $\mathrm{O}_{3}$ and peroxides), $\mathrm{O}_{3} 50 \mathrm{ppbv}$ (O plot), $\mathrm{O}_{3} 50$ ppbv and peroxides 2-3 ppbv (OP1 plot) and $\mathrm{O}_{3} 50$ ppbv and peroxides 4-5 ppbv (OP2 plot). We found that combined $\mathrm{O}_{3}$ and several ppbv peroxides (OP2 plot) caused more severe damage than the $\mathrm{OP} 1$ plot and single $\mathrm{O}_{3}$ (O plot) to leaf injury, chlorophyll content and photosynthetic rate, and reduced total dry weight and pod dry weight. In combined $\mathrm{O}_{3}$ and peroxides exposure, SJ5 showed the most sensitive cultivar in leaf injury, photosynthetic rate, biomass and pod dry weight, while CM showed less sensitivity for photosynthetic rate and pod dry weight.
\end{abstract}

Key words: Ozone, Peroxides, Photosynthetic rate, Soybean, Visible leaf injury.

\section{Introduction}

Ozone $\left(\mathrm{O}_{3}\right)$ is a secondary pollutant that has been reaching high concentrations in the Earth's troposphere (Voulgarakis et al., 2011). It has been recognized as one of the most damaging air pollutants (Tompson, 1992) in recent years. In the last century, the concentrations of $\mathrm{O}_{3}$ increased up to $80 \mathrm{ppbv}$ (Wang et al., 2006) and have been increasing in many places in the world (Voulgarakis et al., 2011). Since $\mathrm{O}_{3}$ formation in the air is accelerated in higher air temperature conditions, it tends to reach a level that causes numerous

Received; May 11, 2012.

Accepted; April 5, 2013.

†Corresponding Author: agrcyc@ku.ac.th decreases in growth and yield under global warming conditions. Ozone is highly reactive, then it binds to plasma membranes and alters metabolism. As a result, chloroplast thylakoid membranes are injured, ribulose1,5-bisphosphate carboxylase/ oxygenase (Rubisco) is degraded and stomatal aperture is poorly regulated (Fiscus et al., 2005; Lu et al., 2009). Long-term exposure to ozone can lead to the reduction of growth and yield. Crop losses by $\mathrm{O}_{3}$ damage in 2000 have been estimated as $\$ 1.8$ to $\$ 3.9$ billion in the United States and $\$ 3.0$ to $\$ 5.5$ billion in China (Dingenen et al., 2009). However, Takami et al. (2003) reported that severe forest decline was seen in the Oku-Nikko Mountains in Japan where $\mathrm{O}_{3}$ concentration was not as high. They also reported that peroxides concentration in the area was high. Then the severe plant damage in 
these areas cannot be fully explained by the effects of $\mathrm{O}_{3}$ alone.

Peroxides always coexist with $\mathrm{O}_{3}$ in the air by the reaction of $\mathrm{O}_{3}$ and volatile organic compounds (VOC). Atmospheric peroxides generally comprise hydrogen peroxide $\left(\mathrm{H}_{2} \mathrm{O}_{2}\right)$ and organic peroxides such as methyl hydroperoxide (MHP) and hydroxymethyl hydroperoxide (HMHP) (Hatakeyama et al., 1993; Takami et al., 2003). In fact, combined $\mathrm{O}_{3}$ and peroxides are much more harmful to some vegetables and other plants than single $\mathrm{O}_{3}$ (Chen et al., 2005; Chen et al., 2010). Recent investigations showed that peroxides concentrations have been increasing (Chen et al., 2008; Chutteang et al., 2012). Terry et al. (1995) suggested that peroxides can damage DNA, lipids, proteins, and plasma membrane that may impact productivity by a reduced photosynthetic rate, inhibited translocation and declined biomass.

The $\mathrm{O}_{3}$ concentration in Asia ranges from 5 to 80 ppbv (Chen et al., 2008; Kang, 2002). The concentrations of gas-phase $\mathrm{H}_{2} \mathrm{O}_{2}$ are found in ranges of 0.02 to 6 ppbv in Japan. (Sakugawa et al., 1990; Takami et al., 2003; Chutteang et al., 2012). The peroxide concentrations were in the order of several ppbv in Nagano Prefecture, Japan (Chen et al., 2008). Chen et al. (2010) reported that exposure to $\mathrm{O}_{3}$ of $50 \mathrm{ppbv}$ in combination with peroxides of 2-3 ppbv caused an extremely severe decrease in the leaf photosynthetic rate and much higher foliar injury of radish than that of 100 ppbv $\mathrm{O}_{3}$ alone.

Soybean (Glycine max (L.) Merr) is an important crop species that is sensitive to $\mathrm{O}_{3}$ (Morgan et al., 2003). Heagle et al. (1998) reported that a moderately high level of $\mathrm{O}_{3}$ (60-100 ppbv) in the mid-Atlantic states of the USA may cause as much as a $40 \%$ loss of soybean yield. However, the sensitivity of plants to $\mathrm{O}_{3}$ and air pollutants varies among genotypes (Akhtar et al., 2010; Betzelberger et al., 2010). Genetic variation in $\mathrm{O}_{3}$ sensitivity was commonly observed in several plant species, for example snap bean (Reitnart and Eason, 2000), tomato (Temple, 1990), potato (Heagle et al., 2003), and soybean (Burkey and Carter, 2009). However, there is no information about cultivar sensitivity of soybeans under combined exposure of $\mathrm{O}_{3}$ and peroxides. Moreover the physiological responses to combined $\mathrm{O}_{3}$ and peroxides are necessary to investigate future crop productivity assessment since atmospheric peroxides concentration will increase in the future. Hence the objectives of the present research are to investigate the single and combined effects of $\mathrm{O}_{3}$ and peroxides on leaf injury and physiological responses, and to compare the soybean cultivar sensitivities.

\section{Materials and Methods}

\subsection{Plant materials}

Two Japanese soybeans, Tachinagaha (TC) and Chamame (CM), and two Thai soybean cultivars, A75 and Sorjor 5 (SJ5) were used. The experiments were conducted two times from December 2010 to March 2011 and December 2011 to March 2012. In these two experiments, methods and procedures were the same. Soybean seeds were seeded in plastic pots of $0.8-\mathrm{L}$ on 16 December 2010 and 22 December 2011 filled with Cumulic Andosols (Melanudand) soil. Fertilizer ( $\mathrm{N}^{-}$ $\mathrm{P}-\mathrm{K}=14-14-14)$ was applied at $5 \mathrm{~g}$ per pot before seeding, and pest control was also applied. The plants were grown under charcoal-filtered air in a glass house for 20 days before the exposure experiments, and the exposure was begun at the third trifoliate leaf stage. Ten plants in ten pots were randomly selected for each treatment. The potted plants were watered twice a day before and after exposure every day.

\subsection{Exposure treatments}

Four outdoor growth chambers (Koito Ltd., Yokohama, Japan), in which the air temperature (day: 06.00 to $18.0025^{\circ} \mathrm{C}$; night: 18.01 to $05.5918^{\circ} \mathrm{C}$ ) and the relative humidity $(70 \%)$ were controlled, were used. The air in the chambers was homogenized by fans. The four experimental plots were the control plot that is $\mathrm{O}_{3}$ and peroxides free (C plot), 50 ppbv $\mathrm{O}_{3}$ plot (O plot), $50 \mathrm{ppbv}$ and 2-3 ppbv peroxides ( $+\alpha$-pinene) plot (OP1 plot), and 50 ppbv $\mathrm{O}_{3}$ and $4-5 \mathrm{ppbv}$ peroxides ( $+\alpha$-pinene) plot (OP2 plot). The C plot was controlled with charcoal-filtered air. Ozone was generated from air by a silent electrical discharge $\mathrm{O}_{3}$ generator (MO-5A, Nihon Ozone Ltd., Kagoshima, Japan). The oxides of nitrogen were completely removed by water filter. The concentration of $\mathrm{O}_{3}$ was regulated by an automatic controlling system (HMC-2000/S; Koito Ltd., Yokohama, Japan) and monitored every 90 seconds. This measurement was performed automatically and continuously. Peroxides were produced by a similar formation in the atmosphere, namely by the reaction of $\mathrm{O}_{3}$ with vaporized $\alpha$-pinene in the chamber (Chen et al., 2005, 2010). The gaseous peroxides in 
each chamber were sampled with a Pyrex glass mist chamber (Cofer et al., 1985) three times a day in the morning, early afternoon, and late afternoon. The concentration of peroxides was measured by a portable RQflex 10 reflectometer (MERCK KGaA, Darmstadt, Germany). Details of the above procedures are explained in Chen et al. $(2005,2010)$ and Chutteang et al. (2012). The exposure was conducted from 9:00 to 16:00 every day.

\subsection{Evaluation of visible leaf injury, SPAD index and chlorophyll content}

Visible foliar injury was evaluated on first trifoliate leaves every two to three days after exposure. Three lateral leaves at the same position for each plant from four plants per plot were evaluated. Visible injury was expressed by its intensity of $0,1,2,3$ and 4 , which represent no injury, chlorosis $<50 \%$ of individual leaf area, chlorosis $>50 \%$ of individual leaf area, necrosis $<50 \%$ of individual leaf area and necrosis $>50 \%$ of individual leaf area, respectively. The SPAD index was measured by a chlorophyll meter (SPAD502, Minolta Camera Co., Ltd., Japan) every 2-3 days. Chlorophyll content was evaluated by the equation from the correlation of the SPAD index and total chlorophyll content for each cultivar. Total chlorophyll contents were measured from leaf disc extract (Moran, 1982). The equation of TC cultivar is $y=0.0107 x^{-} 0.07 \quad(n=30)$, CM cultivar is $y=0.0142 x-0.08 \quad(n=25)$, SJ5 cultivar is $y=0.0095 x-0.05(n=27)$, and A75 cultivar is $y=$ $0.0513 x-0.10(n=25)$.

\subsection{Measurements of leaf gas exchange}

Leaf gas exchange was measured on the first trifoliate leaf by a photosynthesis measurement system (LI6400-40 by LI-COR, Nebraska, U.S.A.) at $10\left(1^{\text {st }}\right.$ measurement), 20 ( $2^{\text {nd }}$ measurement), and 30 ( $3^{\text {rd }}$ measurement) days after exposure in the second experiment from four plants in each plot and cultivar. The leaf chamber environment conditions were set to optimal conditions for stomatal opening and light saturation condition that are under PAR $1500 \mu \mathrm{mol}$ PPFD $\mathrm{m}^{-2} \mathrm{~s}^{-1}, \mathrm{CO}_{2} 400 \mu \mathrm{molCO}_{2} \mathrm{~mol}^{-1}$, temperature $25^{\circ} \mathrm{C}$, and $\mathrm{RH} 65-70 \%$. The light-saturated photosynthetic rate $(\mathrm{A})$, transpiration rate $(\mathrm{E})$, stomatal conductance (gs), and intercellular $\mathrm{CO}_{2}$ concentration $(\mathrm{Ci})$ were evaluated. The $1^{\text {st }}$ and $3^{\text {rd }}$ measurements were performed under sunny conditions, but the $2^{\text {nd }}$ measurement was under cloudy conditions, so in the present research the results of the $1^{\text {st }}$ and $3^{\text {rd }}$ measurements were used in the case of correlations between $\mathrm{A}$ and gs and $\mathrm{Ci}$.

\subsection{Measurement of biomass}

The biomasses of root, leaf, stem, and pod were measured on Day 50 (CM) and on Day 55 (A75, TC and SJ5) when the growth stage was R6 and the pod contained green seed in the pod cavities (Fer and Caviness, 1977). Four plants in each plot and cultivars were randomly selected. We could not continue the experiment further because some plants started to die due to severe damage. Each organ was weighed after oven drying at $80^{\circ} \mathrm{C}$ for 3 days.

\subsection{Data analysis}

The present research experiments were conducted in two years, and these data sets were combined and averaged since no significant difference was observed. Thus all results shown in the present article were based on the two-year data sets except leaf gas exchange. Statistical data analysis was performed with R 2.13.1 Software. Analysis of variance (ANOVA) was used to test the effects of experimental plots and cultivars. Tukey's HSD test was performed to identify significant differences in a cultivar. Sample numbers were eight plants per plot per cultivar.

\section{Results}

\subsection{Visible foliar injury}

In the $\mathrm{O}$ plot, the silver stipples were found in the early stage after fumigation and they turned to brown spot, and necrosis gradually appeared. However, brown spot and necrosis appeared much earlier in the OP1 and OP2 plots than the O plot. Some typical symptoms of visible foliar injury in combined $\mathrm{O}_{3}$ and peroxides (OP2) are shown in Fig. 1. The intensity of visible foliar injury of four soybean cultivars showed a similar pattern in which the OP2 plot caused more severe damage than those of the OP1 plot and O plot (Fig. 2). SJ5 was more sensitive than CM, A75 and TC in the OP1 and OP2 plots. In the O plot, A75 cultivar was less sensitive than TC, SJ5 and CM (Fig. 3).

\subsection{Chlorophyll content}

The total chlorophyll content of the OP1 and OP2 plots showed a different response to that of the $\mathrm{O}$ plot. And the $\mathrm{O}$ plot showed two step responses to the $\mathrm{O}_{3}$ dose while the OP1 and OP2 plots showed a linear response to peroxide dose as shown in Fig. 4. At first, the total chlorophyll content of the O plot was gradually decreased and then rapidly decreased. The total 


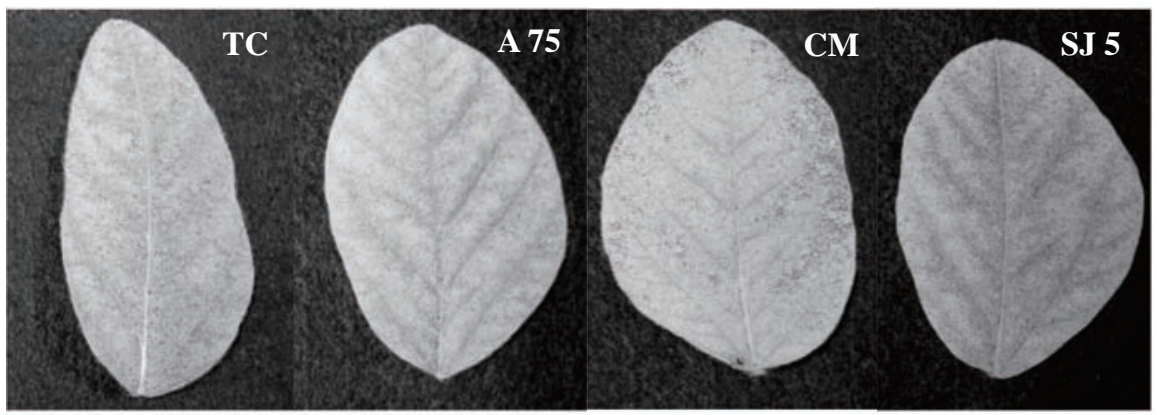

Fig. 1. A typical symptom of visible leaf injury under combined $\mathrm{O}_{3}$ and peroxides after 30 days of exposure in OP2 plot.
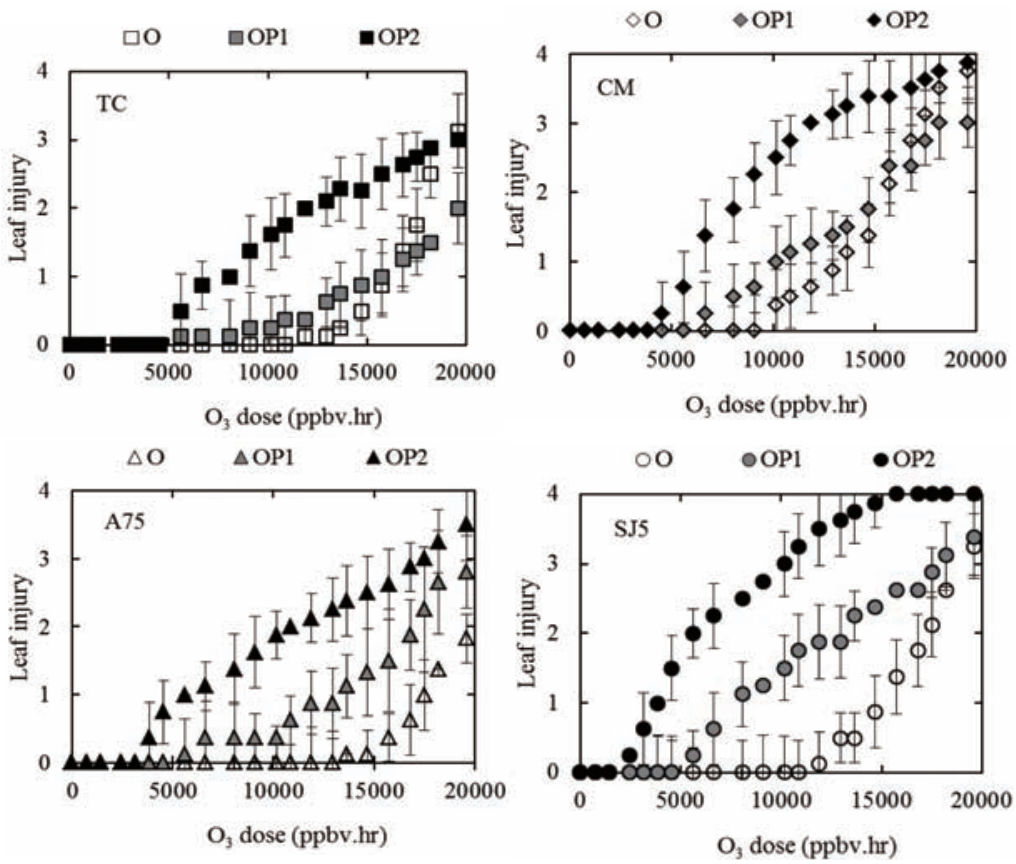

Fig. 2. $\mathrm{O}_{3}$ dose responses of visible leaf injury in four soybean cultivars The vertical bars of symbols are standard deviations.

chlorophyll content of the OP1 and OP2 plots rapidly decreased from just after exposure (Fig. 4). In the case of the $\mathrm{O}$ plot, $\mathrm{CM}$ showed the most sensitivity, while A75 and SJ5 seem to be less sensitive. In the OP1 and OP2 plots, SJ5 and CM showed high sensitivity, while TC showed less sensitivity (Fig. 4). The order of cultivar sensitivity in the total chlorophyll content in the $\mathrm{O}$, OP1 and OP2 plots was similar to those of visible leaf injury.

\subsection{Leaf gas exchange}

Figure 5 shows a decrease in the net photosynthetic rate. The OP2 plot showed a much more highly reduced net photosynthetic rate than the OP1 and O plots at 10 and 20 days after exposure. SJ5 was the most sensitive in the O, OP1 and OP2 plots except on Day 30. TC showed less sensitivity in the O plot, but CM showed less sensitivity in both the OP1 and OP2 plots (Fig. 5). 

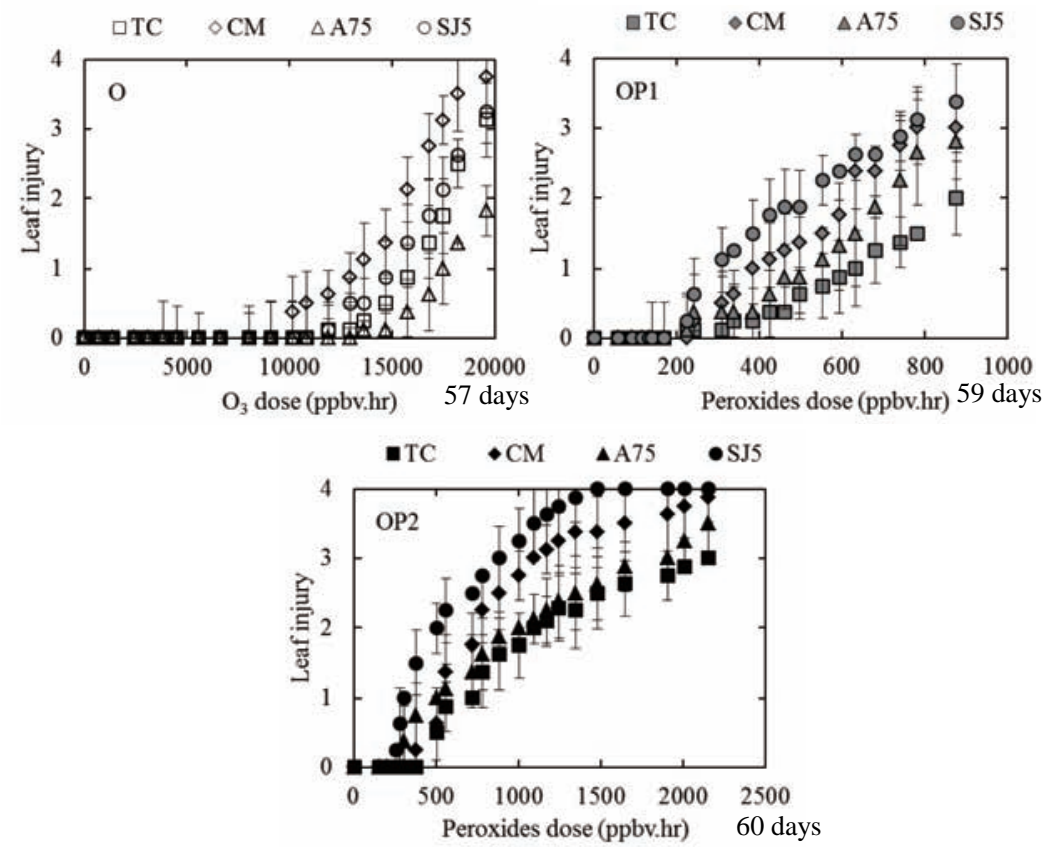

Fig. 3. Comparison of visible leaf injury sensitivity The vertical bars of symbols are standard deviations.
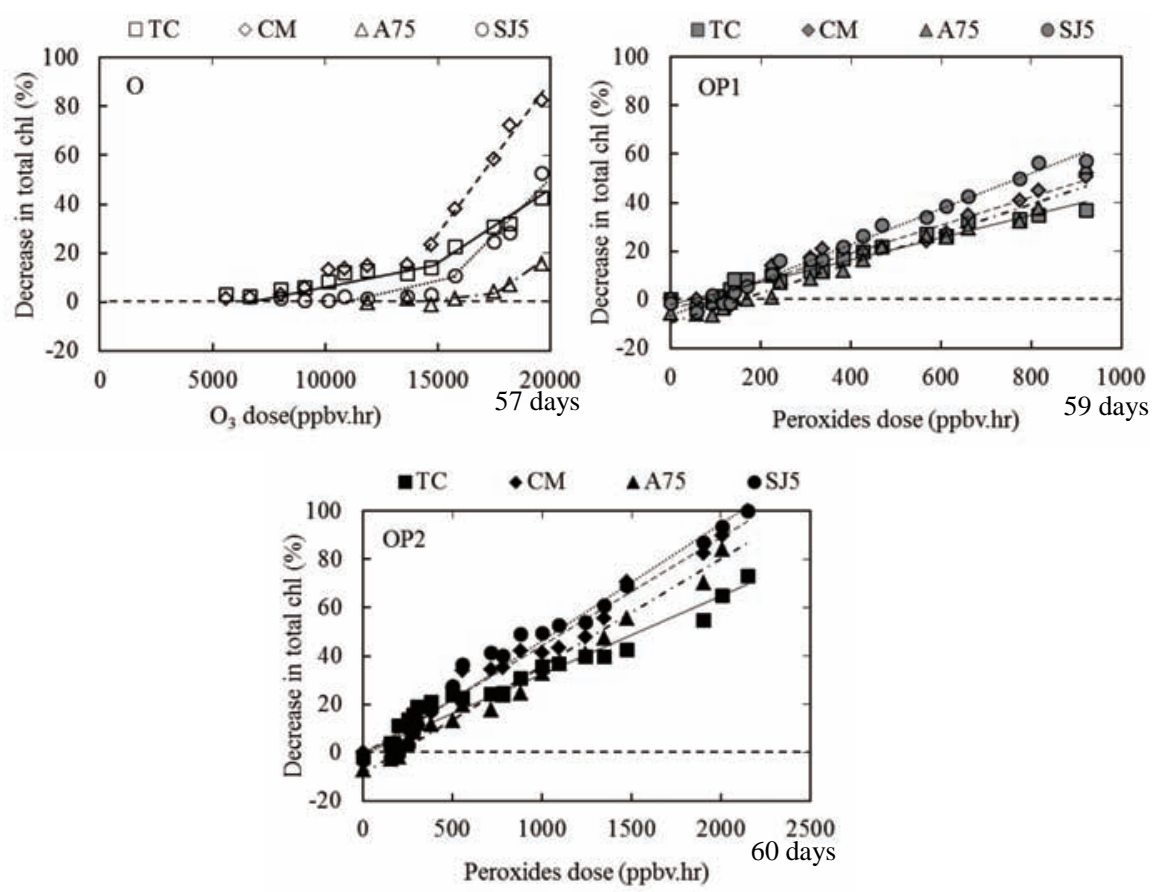

Fig. 4. Comparison of decrease in total chlorophyll content (Chl). 


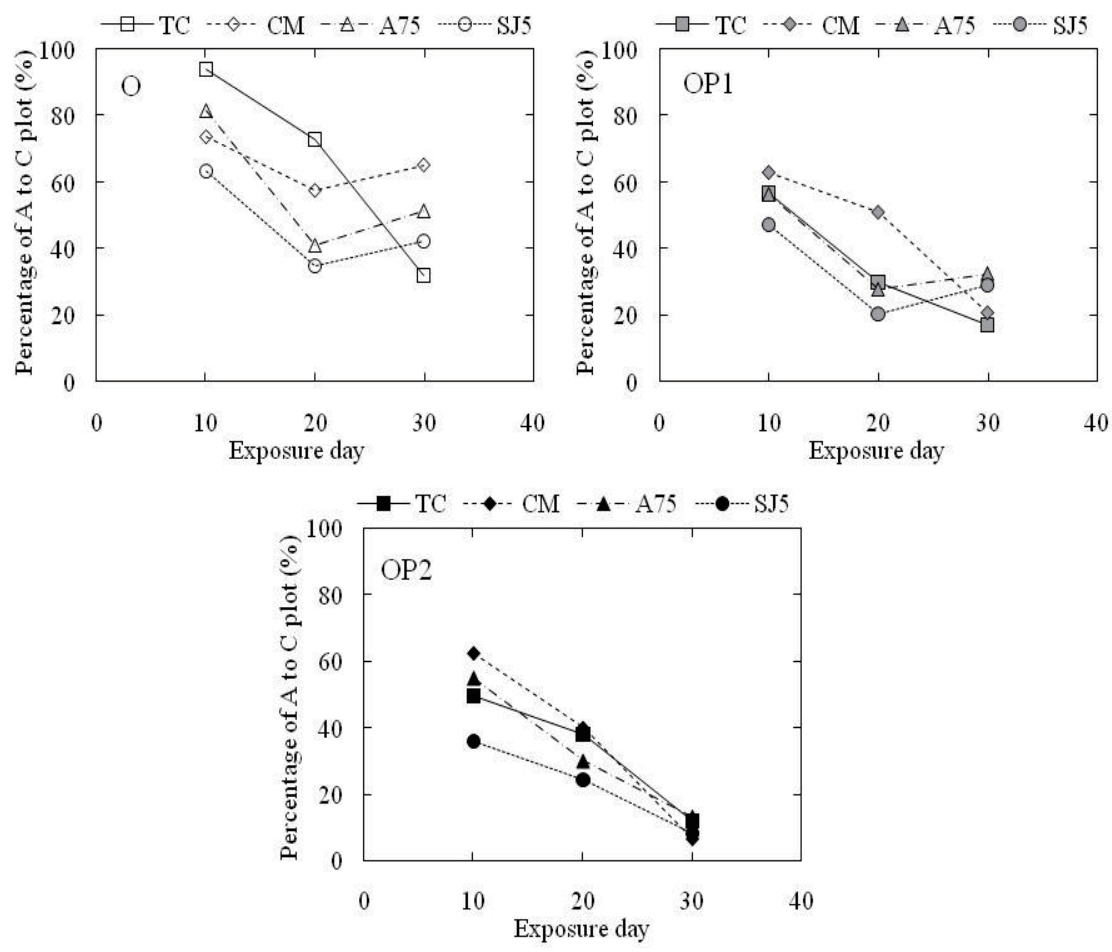

Fig. 5. Percentage of net photosynthetic rate (A) to C plot of four soybean cultivars The data were measured only in the second year experiment.

Correlations between $\mathrm{A}$ and gs and $\mathrm{Ci}$ are shown in Fig. 6. The A versus gs relationship in the $\mathrm{C}$ plot is shown by the dotted line (-) circle in Fig.6a and its position in the figure did not change as shown in Fig. 6c. This means that the $\mathrm{A}$ versus gs relationship in the $\mathrm{C}$ plot was almost the same for 20 days from 10 days and 30 days after exposure. Whereas in the OP1 and OP2 plots, shown respectively by a two-dot chain line (...-) circle and solid line (-) circle, both A and gs values of all cultivars decreased during 20 days. This means that $\mathrm{A}$ values of all cultivars decreased followed by the decrease in gs when the exposure continued for more 20 days. In this case the decreases in A and gs values in the OP2 plot were more than the OP1 plot.

As for the position of the A versus gs relationship in the $\mathrm{O}$ plot shown by the dashed line (----) circle, A and gs_values of some cultivars changed greatly during 20 days, and then the A versus gs relationship became a positive correlation at 30 days after exposure as shown in Fig. 6c.

In the case of the $\mathrm{C}$ plot, the $\mathrm{A}$ versus $\mathrm{Ci}$ relationship did not change during 20 days as shown in Fig. $6 \mathrm{~b}$ and
Fig. 6d. Whereas in the OP1 and OP2 plots, A of all cultivars decreased but $\mathrm{Ci}$ increased for 20 days. Especially this tendency of the OP2 plot was much greater than the OP1 plot. In the O plot such tendency was much smaller than the OP1 plot (See Fig. 6b and Fig. 6d). As a whole, in the O plot, A was reduced by gs, but not by $\mathrm{Ci}$. In the OP plots, A was reduced by both low gs and high $\mathrm{Ci}$.

We also found that the sensitive cultivar, SJ5, showed the highest gs value in the $\mathrm{C}, \mathrm{O}$ and $\mathrm{OP} 1$ plots at 10 days after exposure and became lowest at 30 days after exposure. Whereas tolerant cultivars, TC and CM, gs showed lower values in each plot except the OP2 plot at 10 days after exposure as shown in Fig.6a. As for $\mathrm{A}$ versus $\mathrm{Ci}$, SJ5 showed the highest $\mathrm{Ci}$ in each $\mathrm{C}$, $\mathrm{O}$ and OP1 plot groups at 10 days after exposure (see Fig. 6b). The present research results showed that the sensitive cultivar (SJ5) highly reacted with single $\mathrm{O}_{3}$ and combined $\mathrm{O}_{3}$ and peroxides much more than tolerant cultivars (TC and CM).

\subsection{Biomass}

The biomasses of four soybean cultivars after 50 

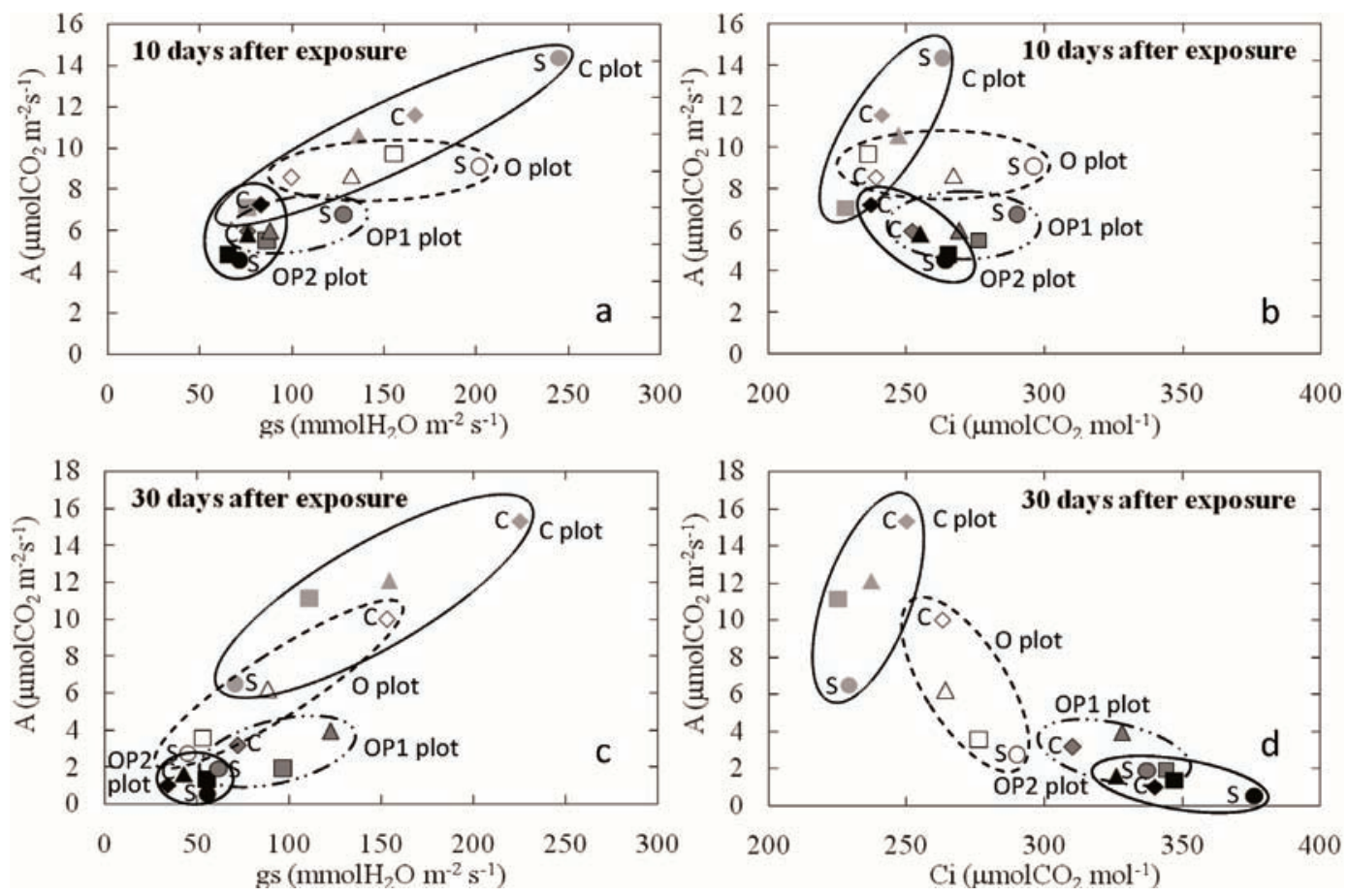

Fig. 6. Correlations between net photosynthetic rate (A) and stomatal conductance (gs) (Fig. 6a and Fig. 6c) and $\mathrm{CO}_{2}$ concentration in intercellular space ( $\mathrm{Ci}$ ) (Fig. $6 \mathrm{~b}$ and Fig. $6 \mathrm{~d}$ ) of four soybean cultivars

$\mathrm{C}$ and $\mathrm{S}$ show $\mathrm{CM}$ and SJ5 cultivars, respectively. The data were measured only in the second year experiment.

C plot : TC $(\square)$ CM $(\diamond)$ A75 $(\triangle)$ SJ5 $(O)$

O plot : TC $(\square)$ CM $(\diamond)$ A75 $(\triangle)$ SJ5 ( O)

OP1 plot : TC $(\square)$ CM $(\diamond)$ A75 $(\triangle)$ SJ5 $(\bigcirc)$

OP2 plot : TC ( $)$ CM $(\diamond)$ A75 ( $\mathbf{\Delta})$ SJ5

days (CM cultivar) and 55 days (TC, A75 and SJ5 cultivars) exposure are shown in Table 1. In TC cultivar, the total dry weights of the $\mathrm{C}$ and $\mathrm{O}$ plots were not significantly different, and the OP1 plot was not clearly different from the $\mathrm{O}$ plot, whereas a $44 \%$ decrease in total dry weight and a $91 \%$ decrease in pod dry weight than the $\mathrm{C}$ plot were found in the OP2 plot. Moreover root dry weight significantly reduced in the OP2 plot. The results of CM cultivar showed that the dry weight of all organs was significantly different among the four plots. The total dry weight was not different between the $\mathrm{C}$ and $\mathrm{O}$ plots, while both the OP1 and OP2 plots caused a 29\% and 55\% reduction in the total dry weight than the C plot. Both the OP1 and OP2 plots caused a $47 \%$ and $49 \%$ reduction in the total dry weight of A75 and $45 \%$ and $59 \%$ in that of SJ5, respectively. As for the total dry weight in the O plot, TC showed the most tolerant cultivar and the other three cultivars showed no significant difference. In the OP1 and OP2 plots, TC was less sensitive while SJ5 was the most sensitive cultivar. Considering pod dry weight, we found that SJ5 was the most decreasing cultivar in O $(30 \%)$, OP1 $(61 \%)$, and OP2 $(96 \%)$, while $\mathrm{CM}$ was the least decreasing cultivar in $\mathrm{O}$ $(14 \%)$, OP1 (45\%) and OP2 (52\%). This may imply that SJ5 was the most sensitive cultivar on total dry weight and pod dry weight, while CM was the less sensitive cultivar on pod dry weight (Table 1). 
Table 1. Effect of $\mathrm{O}_{3}$ and peroxides on dry weight of four soybean cultivars (Mean of eight replicates $\pm \mathrm{SD}$.)

\begin{tabular}{|c|c|c|c|c|c|c|c|c|}
\hline \multirow{2}{*}{ Cultivars } & \multirow{2}{*}{ Plots } & \multicolumn{7}{|c|}{ Dry weight $\left(\mathrm{g} \mathrm{plant}^{-1}\right)$} \\
\hline & & Root & Petiole & Stem & Leaf & Flower & Pod & Total \\
\hline \multirow{4}{*}{ TC } & $\mathrm{C}$ & $1.88 \pm 0.59^{\mathrm{a}}$ & $0.34 \pm 0.19$ & $1.15 \pm 0.42$ & $1.48 \pm 0.78$ & $0.12 \pm 0.14$ & $2.80 \pm 0.81^{\mathrm{a}}$ & $7.77 \pm 1.29^{\mathrm{a}}$ \\
\hline & $\mathrm{O}$ & $1.81 \pm 0.67^{\mathrm{a}}$ & $0.31 \pm 0.15$ & $1.02 \pm 0.42$ & $1.41 \pm 0.67$ & $0.10 \pm 0.14$ & $2.35 \pm 0.95^{\mathrm{ab}}$ & $6.99 \pm 1.17^{\mathrm{ab}}$ \\
\hline & OP1 & $1.51 \pm 0.27^{\mathrm{ab}}$ & $0.29 \pm 0.06$ & $1.09 \pm 0.32$ & $1.14 \pm 0.27$ & $0.17 \pm 0.13$ & $1.45 \pm 0.85^{\mathrm{b}}$ & $5.65 \pm 1.65^{\mathrm{bc}}$ \\
\hline & $\mathrm{OP} 2$ & $1.11 \pm 0.40^{\mathrm{b}}$ & $0.29 \pm 0.09$ & $1.04 \pm 0.16$ & $1.49 \pm 0.29$ & $0.16 \pm 0.06$ & $0.25 \pm 0.17^{\mathrm{c}}$ & $4.33 \pm 0.80^{c}$ \\
\hline ANOVA & & $* *$ & ns & ns & ns & ns & $* *$ & $* *$ \\
\hline \multirow{4}{*}{ CM } & $\mathrm{C}$ & $1.18 \pm 0.19^{\mathrm{ab}}$ & $0.35 \pm 0.17^{\mathrm{a}}$ & $1.01 \pm 0.22^{\mathrm{a}}$ & $1.31 \pm 0.67^{\mathrm{a}}$ & - & $3.73 \pm 0.66^{\mathrm{a}}$ & $7.58 \pm 1.82^{\mathrm{a}}$ \\
\hline & $\mathrm{O}$ & $1.24 \pm 0.20^{\mathrm{a}}$ & $0.23 \pm 0.05^{\mathrm{ab}}$ & $0.90 \pm 0.13^{\mathrm{a}}$ & $0.87 \pm 0.27^{\mathrm{ab}}$ & - & $3.22 \pm 0.24^{\mathrm{a}}$ & $6.45 \pm 0.49^{\mathrm{ab}}$ \\
\hline & OP1 & $0.91 \pm 0.18^{\mathrm{b}}$ & $0.29 \pm 0.08^{\mathrm{a}}$ & $0.86 \pm 0.17^{\mathrm{a}}$ & $1.25 \pm 0.17^{\mathrm{a}}$ & - & $2.07 \pm 0.62^{b}$ & $5.37 \pm 1.18^{\mathrm{b}}$ \\
\hline & OP2 & $0.58 \pm 0.16^{\mathrm{c}}$ & $0.12 \pm 0.04^{\mathrm{b}}$ & $0.47 \pm 0.10^{\mathrm{b}}$ & $0.46 \pm 0.20^{\mathrm{c}}$ & - & $1.79 \pm 0.44^{\mathrm{b}}$ & $3.42 \pm 0.86^{\mathrm{c}}$ \\
\hline ANOVA & & $* *$ & ** & ** & $* *$ & & $* *$ & $* *$ \\
\hline \multirow{4}{*}{ A 75} & $\mathrm{C}$ & $1.57 \pm 0.16^{\mathrm{a}}$ & $0.34 \pm 0.17^{\mathrm{a}}$ & $1.19 \pm 0.47^{\mathrm{a}}$ & $1.78 \pm 0.91^{\mathrm{a}}$ & - & $4.27 \pm 0.39^{\mathrm{a}}$ & $9.15 \pm 1.95^{\mathrm{a}}$ \\
\hline & $\mathrm{O}$ & $1.34 \pm 0.21^{\mathrm{a}}$ & $0.30 \pm 0.12^{\mathrm{ab}}$ & $1.13 \pm 0.19^{\mathrm{a}}$ & $1.45 \pm 0.60^{\mathrm{ab}}$ & - & $3.49 \pm 0.55^{\mathrm{a}}$ & $7.70 \pm 0.73^{\mathrm{a}}$ \\
\hline & OP1 & $0.74 \pm 0.24^{b}$ & $0.20 \pm 0.06^{\mathrm{b}}$ & $0.72 \pm 0.19^{b}$ & $0.86 \pm 0.33^{\mathrm{b}}$ & - & $2.26 \pm 0.47^{b}$ & $4.78 \pm 1.06^{\mathrm{b}}$ \\
\hline & OP2 & $0.81 \pm 0.14^{\mathrm{b}}$ & $0.25 \pm 0.07^{\mathrm{ab}}$ & $0.90 \pm 0.23^{\mathrm{ab}}$ & $1.13 \pm 0.36^{\mathrm{ab}}$ & - & $1.55 \pm 0.48^{\mathrm{b}}$ & $4.63 \pm 0.59^{\mathrm{b}}$ \\
\hline ANOVA & & $* *$ & $*$ & $*$ & $* *$ & & $* *$ & $* *$ \\
\hline \multirow{4}{*}{ SJ 5} & $\mathrm{C}$ & $1.59 \pm 0.61^{\mathrm{a}}$ & $0.50 \pm 0.35$ & $1.12 \pm 0.52^{\mathrm{a}}$ & $1.71 \pm 0.88$ & $0.00 \pm 0.01$ & $3.01 \pm 0.12^{\mathrm{a}}$ & $7.92 \pm 1.97^{\mathrm{a}}$ \\
\hline & $\mathrm{O}$ & $1.42 \pm 0.38^{\mathrm{a}}$ & $0.44 \pm 0.25$ & $1.10 \pm 0.46^{\mathrm{ab}}$ & $1.64 \pm 0.78$ & $0.01 \pm 0.02$ & $2.11 \pm 0.90^{\mathrm{b}}$ & $6.72 \pm 1.11^{\mathrm{a}}$ \\
\hline & OP1 & $0.87 \pm 0.19^{b}$ & $0.34 \pm 0.15$ & $0.77 \pm 0.18^{b}$ & $1.21 \pm 0.37$ & $0.01 \pm 0.03$ & $1.17 \pm 0.35^{\mathrm{c}}$ & $4.37 \pm 1.11^{b}$ \\
\hline & OP2 & $0.68 \pm 0.22^{b}$ & $0.34 \pm 0.09$ & $0.79 \pm 0.15^{\mathrm{ab}}$ & $1.27 \pm 0.22$ & $0.02 \pm 0.03$ & $0.11 \pm 0.06^{\mathrm{d}}$ & $3.25 \pm 0.57^{b}$ \\
\hline ANOVA & & $* *$ & ns & ** & ns & ns & $* *$ & ** \\
\hline
\end{tabular}

CM was harvested on 50 days after exposure, while other cultivars were harvested on 55 days after exposure. Twoway ANOVA: $* * \mathrm{P}<0.01, * \mathrm{P}<0.05$, NS $=$ not significant. Values with different letters are significantly different at $\mathrm{P}<0.05$.

\section{Discussion}

\subsection{Visible foliar injury}

Several scientists found that soybean had genetic variation in $\mathrm{O}_{3}$ responses (Foy et al., 1995; Robinson and Britz, 2000; Morgan et al., 2003). Burkey and Carter (2009) reported that ancestral lines of soybean in the USA and Canada showed wide ranges of visible leaf injury to high $\mathrm{O}_{3}$. The symptom of visible leaf injury in the O, OP1 and OP2 plots was similar to that in Burkey and Carter (2009). The intensity of visible leaf injury showed severe damage in combined $\mathrm{O}_{3}$ and peroxides more than single $\mathrm{O}_{3}$. Similar results were found by Chen et al. (2010), Chutteang et al. (2011) and Na-ngern et al. (2011). Moreover the sensitivity of visible leaf injury was different among four soybean cultivars and the orders of cultivar sensitivity were different between single $\mathrm{O}_{3}$ and combined $\mathrm{O}_{3}$ and peroxides. The cultivar sensitivity was identified as three groups consisting of tolerance, moderated tolerance, and sensitivity in both single $\mathrm{O}_{3}$ and combined $\mathrm{O}_{3}$ and peroxides. This implies that some injury mechanisms may be different between single $\mathrm{O}_{3}$ and combined $\mathrm{O}_{3}$ and peroxides.

\subsection{Chlorophyll content}

Chen et al. (2010) reported that the total chlorophyll content of Japanese radish was reduced by the fumigation of combined 50 ppbv $\mathrm{O}_{3}$ and sub-ppbv peroxides and by a high level of $\mathrm{O}_{3}$ concentration. Similar results were found in the present research that a much more severe reduction was observed in the OP1 and OP2 plots than the O plot (Fig. 4). This implies that low $\mathrm{O}_{3}$ concentrations cause less reduction in chlorophyll content but sub-ppbv peroxides concurrent with 50 ppbv $\mathrm{O}_{3}$ caused severe damage in photosynthetic pigment. Similar results were found by Inada et al. (2008) that a low $\mathrm{O}_{3}$ condition did not reduce chlorophyll content in two Japanese rice cultivars.

\subsection{Leaf gas exchange}

As for soybean, Robinson and Britz (2000) revealed 
that short term exposure to a moderate level of ozone did not significantly affect $\mathrm{CO}_{2}$ assimilation and stomatal conductance per unit leaf area. Fiscus et al. (2005) reported that reduction in $\mathrm{CO}_{2}$ fixation under long-term $\mathrm{O}_{3}$ exposure is mainly restricted by Rubisco activity. The present result showed a similar result in TC whose cultivar was less sensitive. The net photosynthetic rate slightly decreased at 10 days after single $\mathrm{O}_{3}$ exposure and highly reduced at 30 days after exposure. On the other hand, the relative net photosynthetic rate to $\mathrm{C}$ plot of sensitive cultivar (SJ5) was about $40 \%$ at 10 days after exposure by single $\mathrm{O}_{3}$. The OP2 plot showed an extremely severe decrease in the net photosynthetic rate. A similar result was found in Japanese radish by Chen et al. (2010) . However, we cannot explain the reason why a more severe reduction of the photosynthetic rate occurred in OP plots than the O plot. Reid et al. (1998) reported that the chronic $\mathrm{O}_{3}$ condition of 80 ppbv $\mathrm{O}_{3}$ affected carbon fixation by decreasing the activity and content of Rubisco in soybean. This implies that 50 ppbv $\mathrm{O}_{3}$ may not cause a severe decrease in carbon fixation, but combined peroxides and $\mathrm{O}_{3}$ are very harmful and cause the significant reduction of carbon fixation.

We found that the sensitive cultivar had a larger gs value than that of the tolerant cultivar in each experimental plot. But these tendencies were not shown at 30 days after exposure as shown in Fig. 6a and Fig. 6c. This may be because the leaves were becoming senescent at 30 days after exposure. Flux of $\mathrm{O}_{3}$ and other gases into the leaf is controlled by stomatal conductance (Fiscus et al., 1997). As for the results mentioned above, $\mathrm{O}_{3}$ and peroxides have a higher possibility of entering into the leaf in sensitive plants than tolerant cultivar and cause more severe damage. Fiscus et al. (2005) suggested that tolerant plants will close the stomata to protect against the absorption of $\mathrm{O}_{3}$ while sensitive plants cannot regulate the stomata. Our results support the suggestion of Fiscus et al. (2005).

The present research results also suggest as shown in Fig. 6 that the net photosynthetic rate of soybean leaf under $50 \mathrm{ppbv} \mathrm{O}_{3}$ alone was reduced by the reduction of gs, but those of combined 50 ppbv $\mathrm{O}_{3}$ and peroxides reduced by both gs and $\mathrm{Ci}$ that relates to carbon fixation.

\subsection{Biomass}

$\mathrm{O}_{3}$ exposure results in decreased photosynthetic carbon assimilation (Morgan et al., 2003;
Betzelberger et al., 2010) . The present research results showed that total dry weight was not significantly decreased under 50 ppbv $\mathrm{O}_{3}$, which is an average $\mathrm{O}_{3}$ concentration in Japan. Obviously, the combined $\mathrm{O}_{3}$ and high peroxides condition caused decreases in the total dry weight of more than $40 \%$ and pod dry weight of more than $50 \%$ in four soybean cultivars. A similar research result was reported by Chen et al. (2010) that the combined effect of $\mathrm{O}_{3}$ and 2-3 ppbv peroxides reduced the biomass of Japanese radish by about $30 \%$. Generally, biomass is primarily regulated by source and sinks strength. Then high reduction in biomass would be caused by more severe damage to visible leaf injury and a higher decrease in the photosynthetic rate in combined $\mathrm{O}_{3}$ and peroxides than single $\mathrm{O}_{3}$. Peroxides and $\mathrm{O}_{3}$ can oxidize some protein and enzyme involved in photosynthesis (Chen et al., 2005; Lu et al., 2009). Then the structure and function of the photosynthetic organ were destroyed after the exposure of the soybean plant to combined $\mathrm{O}_{3}$ and peroxides. The chlorophyll content was also degraded and the stomatal aperture could not be regulated. These caused a significant decline in the photosynthetic rate and synthesis of dry matter, resulting in a considerable decrease in biomass. TC cultivar showed less reduction in the total dry weight but a high decrease in pod dry weight while $\mathrm{CM}$ which showed more reduction in the total dry weight than that of TC but could maintain pod productivity (Table 1 ). Similar results were found by Betzelberger et al. (2010) who suggested that there were various mechanisms of tolerance to high $\mathrm{O}_{3}$ concentration within soybean germplasm. For future high $\mathrm{O}_{3}$ and peroxides condition, SJ5 may not be a suitable cultivar since reduction in crop yield is high, but CM may have less damage to production and would be a suitable cultivar. Our results showed that CM could maintain biomass and pod yield, although it induced more severe damage on leaf injury and a greater decrease in the total chlorophyll content.

In terms of dry matter distribution, TC, A75 and SJ5 showed that dry matter of pod was decreased, while the fraction of dry matter of leaf, petiole and stem dry mass was increased in OP plots. Marcelis (1996) demonstrated that the dry matter partitioning among the sinks of a plant is primarily regulated by the sink organs and depends on plant genetics and environment. Sensitive cultivars could not produce pods and seeds, but could produce leaf and stem biomass. 


\section{Conclusion}

Our results showed that single $\mathrm{O}_{3}$ caused leaf injury, chlorophyll degradation, low stomatal conductance, and low photosynthetic rate, but single $\mathrm{O}_{3}$ did not cause more total biomass reduction than the $\mathrm{C}$ plot. Several ppbv peroxides coexisting with $50 \mathrm{ppb} \mathrm{O}_{3}$ induced a significant increase in leaf injury, and also a significant reduction in net photosynthetic rates and biomass than single $50 \mathrm{ppbv} \mathrm{O}_{3}$. It was found that $\mathrm{SJ} 5$ is the most sensitive cultivar while CM was the least sensitive in both single $\mathrm{O}_{3}$ and combined $\mathrm{O}_{3}$ and peroxides from the perspective of pod yield. It was also found that the sensitive cultivar showed higher gs and higher $\mathrm{Ci}$ than tolerant cultivars in each experimental plot on A versus gs and A versus Ci relationships after 10 days of exposure.

In conclusion, the true injury and stress on physiological function in the field cannot be evaluated if peroxides are ignored, and the information about the cultivar sensitivity should be studied in more detail for future conditions of increasing peroxides and $\mathrm{O}_{3}$ concentrations under global warming.

\section{Acknowledgements}

We are thankful to Prof., Dr. Onwana-Agyeman Siaw for providing English correction. We acknowledge the editor and two anonymous reviewers for their helpful suggestions for improving the original manuscript. C. Chutteang and P. Na-ngern are grateful to the Ministry of Education, Culture, Sports, Science and Technology (MEXT) through the Education Program for Field-Oriented Leaders in Environmental Sectors in Asia and Africa (FOLENS program) in Tokyo University of Agriculture and Technology for awarding the scholarship. We wish to thank Prof. Isao Ogiwara of the Horticulture laboratory, Tokyo University of Agriculture and Technology for technical and equipment support. The present study is financially supported partly by the S-8 project of the Ministry of the Environment in 2010 and 2011.

\section{References}

Akhtar, N., Yamaguchi, M., Inada, H., Hoshino, D., Kondo, T., Fukami, M., Funada, R., and Izuta, T., 2010: Effects of ozone on growth, yield and leaf gas exchange rates of four Bangladeshi cultivars of rice (Oryza sativa L.). Environ. Pollut., 158 (9), 2970-
2976.

Betzelberger, A. M., Gillespie, K. M., Mcgrath, J. M., Koester, R. P., Nelson, R. L., and Ainsworth, E. A., 2010: Effects of chronic elevated ozone concentration on antioxidant capacity, photosynthesis and seed yield of 10 soybean cultivars. Plant, Cell Environ., 33, 1569-1581.

Burkey, K. O., and Carter Jr, T. E., 2009: Foliar resistance to ozone injury in the genetic base of U.S. and Canadian soybean and prediction of resistance in descendent cultivars using coefficient of percentage. Field Crop. Res., 111, 207-217.

Chen, X., Aoki, M., Takami, A., Chai, F., and Hatakeyama, S., 2010: Effect of ambient level gasphase peroxides on foliar injury, growth, and net photosynthesis in Japanese radish (Raphanus sativus). Environ. Pollut., 158, 1675-1679.

Chen, X., Aoki, M., Zhang, S., Zhang, J., Nozoe, S., Komori, D., Takami, A., and Hatakeyama, S., 2008: Observation of hydrogen peroxide concentrations in a Japanese red pine forest. J. Atmos. Chem., 60, 3749.

Chen, X., Takami, A., Hatakeyama, S., Horie, K., and Aoki, M., 2005: The toxicity of peroxides to several plants by atmospheric level concentration in the presence of Ozone. J. Agric. Meteorol., 60(5), 953-956.

Chutteang, C., Na-Ngern, P., Aoki M., Takemasa F., Marushima R., Zhenrui G., Chaichana N., and Pakoktom T., 2011: Effect of ozone and peroxides on leaf injury and physiological responses of two Japanese and two Thai soybean cultivars. Proceeding of CIGR International Symposium on Sustainable Bioproduction-Water, Energy, and Food, 19-23 September 2011, Tokyo Hall Hunabori, Tokyo, Japan, 23ESO12-02, pp.7

Chutteang, C., Na-Ngern, P., Marushima, R., Aoki, M., Chaichana, N., and Pakoktom, T., 2012: Measurements of hydrogen peroxides concentration in Tokyo and Thailand. J. Agric. Meteorol., 68 (1) , 45-53.

Cofer, W. R., Collins, G. C., and Talbot, R. W., 1985: Improved aqueous scrubber for collection for soluble atmospheric trace gases. Environ. Sci. Technol., 19, 557-560.

Dingenen, R. V., Dentener, F. J., Raes, F., Krol, M. C., Emberson, L., and Cofala, J., 2009: The global impact of ozone on agricultural crop yield under current and future air quality legislation. Atmos. Environ., 43, 604-618. 
Fiscus, E. L., Booker, F. L., and Burkey, K. O., 2005: Crop responses to ozone: uptake, models of action, carbon assimilation and partitioning. Plant Cell Environ., 28, 997-1011.

Fiscus, E. L., Reid, C. D., Miller, J. E., and Heagle, A. S., 1997: Elevated $\mathrm{CO}_{2}$ reduces $\mathrm{O}_{3}$ flux and $\mathrm{O}_{3}$ induced yield losses in soybeans: possible implications for elevated $\mathrm{CO}_{2}$ studies. J. Exp. Bot., 48 (307), 307-313.

Foy, C. D., Lee, P. H., Rowland, R. A., and Devine, T. E., 1995: Ozone tolerances of soybean cultivars and near isogenic lines in a fumigation chamber. $J$. Plant Nutr., 18(4) , 649-667.

Hatakeyama, S., Lai, H. P., Gao, S. D., and Murano, K., 1993: Production of hydrogen peroxide and organic hydroperoxides in the reactions of ozone with natural hydrocarbons in air. Chem. Lett.,1287-1290.

Heagle, A. S., Miller, J. E., and Pursley, W. A., 1998: Influence of ozone stress on soybean response to carbon dioxide enrichment: III yield and seed quality. Crop Sci., 38 (1), 128-134.

Healgle, A. S., Miller, J. E., and Pursley, W. A., 2003: Growth and yield responses of potato to mixtures of carbon dioxide and ozone. J. Environ. Qual., 32(5), 1603-1610.

Inada, H., Yamaguchi, M., Satoh, R., Hoshino, D., Nagasawa, A., Negishi, Y., Nouchi, I., Kobayashi, K., and Izuta, T., 2008: Effects of ozone on photosynthetic components and radical scavenging system in leaves of rice (Oryza sativa L.). J. Agric. Meteorol., 64 (4), 243-255.

Kang, C. M., Han, J. S., and Sunwoo, Y., 2002: Hydrogen peroxide concentrations in ambient air of Soal, Korea. Atmos. Environ., 36, 5509-5516.

Lu, T., He, X., Chen, W., Yan, K., and Zhao, T., 2009: Effects of elevated $\mathrm{O}_{3}$ and or elevated $\mathrm{CO}_{2}$ on lipid peroxidation and antioxidant systems in Ginkgo biloba leaves. Bull. Environ. Contam. Toxicol., 83, 92-96.

Marcelis, L. F. M., 1996: Sink strength as a determinant of dry matter partitioning in the whole plant. $J$. Exp. Bot., 47, 1281-1291.

Moran, R. 1982: Formulae for determination of chlorophyll pigments extracted with N,N- Dimethylformamide. Plant Physiol., 69, 1376-1381.

Morgan, P. B., Ainsworth, E. A., and Long, S. P., 2003: How does elevated ozone impact soybean? A meta-analysis of photosynthesis, growth and yield Plant, Cell and Environ., 26, 1317-1328.

Na-ngern, P., Chutteang, C., Aoki M., Takemasa, F., Marushima, R., Zhenrui, G., Pakokthom, T., 2011:
Effect of ozone and peroxides on Thai and Japanese rice visible foliar injuries. Proceeding of CIGR International Symposium on Sustainable Bioproduction-Water, Energy, and Food, 19-23 September 2011, Tokyo Hall Hunabori, Tokyo, Japan, 23ESO12-01, pp.4

Reid, C. D., Ficus, E. L., and Burkey, K. O., 1998: Combined effects of chronic ozone and elavated $\mathrm{CO}_{2}$ on Ribisco activity and leaf components in soybean (Glycine max). J. Exp. Bot., 49 (329), 19992011.

Reitnert, R. A., and Eason, G., 2000: Genetic control of $\mathrm{O}_{3}$ sensitivity in a cross between two cultivars of snap bean. J. Am. Soc. Hortic. Sci., 125, 222-227.

Robinson, J. M., and Britz, S. J, 2000: Tolerant of a field grown soybean cultivar to elevated ozone level is concurrent with higher leaflet ascorbic acid level, higher ascorbate-dehydroascorbate redox status, and long term photosynthetic productivity. Photosynth. Res., 64, 77-87.

Sakugawa, H., Tsai, W., Kaplan, I. R., and Cohen, Y., 1990: Factors controlling the photochemical generation of gaseous $\mathrm{H}_{2} \mathrm{O}_{2}$ in the Los Angeles atmosphere. Geophys. Res. Lett.,17, 93-96.

Takami, A., Shiratori, N., Yonekura, H., and Hatakeyama, S., 2003: Measurement of hydrogen peroxides and ozone in Oku-Nikko area. Atmos. Environ., 37, 3861-3872.

Temple, P. J., 1990: Growth and yield responses of processing tomato (Lycopersicon esculentum Mill) cultivars to ozone. Environ. Exp. Bot., 30 (3), 283291.

Terry, G. M., Stokes, N. J., Lucas, P. W., and Hewitt, C. N., 1995: Effects of reactive hydrocarbons and hydrogen peroxide on antioxidant activity in cherry leaves. Environ. Pollut., 88, 19-26.

Tompson, A. M. 1992: The oxidizing capacity of the earth's atmosphere probable past and future changes. Sci., 256 (5060) , 1157-1165.

Voulgarakis, A., Hadjinicolaou, P., and Pyle, J. A., 2011: Increases in global tropospheric ozone following an El Nino event: Examining stratospheric ozone variability as a potential driver. Atmos. Sci. Lett., 12, 228-232.

Wang, H., Zhou, L., and Tang, X., 2006: Ozone concentrations in rural regions of the Yangtze Delta in China. J. Atmos. Chem., 54, 255-265. 